\title{
Perfil sociodemográfico e condições de saúde e trabalho dos professores de nove escolas estaduais paulistas*
}

\author{
SOCIO-DEMOGRAPHIC PROFILE AND HEALTH AND WORKING CONDITIONS OF \\ TEACHERS OF NINE STATE OF SÃO PAULO PUBLIC SCHOOLS
}

\author{
PERFIL SOCIODEMOGRÁFICO Y LAS CONDICIONES DE SALUD Y TRABAJO DE \\ PROFESORES DE NUEVE ESCUELAS ESTATALES PAULISTAS
}

\author{
Tatiana Giovanelli Vedovato ${ }^{1}$, Maria Inês Monteiro ${ }^{2}$
}

\begin{abstract}
RESUMO
Estudo transversal realizado em nove escolas estaduais de Campinas e São José do Rio Pardo, com 258 professores com o objetivo de caracterizar o perfil sociodemográfico, estilos de vida, condições de saúde e de trabalho. A amostra foi composta por mulheres $(81,8 \%)$ e homens $(18,2 \%)$, sendo casados (60,8\%), com média de idade de 41,4 anos (DP 9,2), que realizavam atividade física $(56,6 \%)$, lazer $(93,4 \%)$ e tarefas domésticas (88,4\%). Quanto à saúde, 20,9\% não dormiam bem à noite; $82,1 \%$ possuíam doença com diagnóstico médico: músculo-esquelética e respiratória $(27,1 \%)$; acidentes e doenças digestivas $(22,1 \%)$ e transtornos mentais $(20,9 \%)$. Tais doenças estavam relacionadas aos riscos relatados: movimentos repetitivos, presença de poeira de giz, trabalho estressante, longas jornadas, atividade em mais de uma escola e baixa remuneração. Concluiu-se que os professores eram expostos a riscos nasescolas e que medidas de promoção à saúde e prevenção deveriam ser tomadas pelos governantes.
\end{abstract}

\begin{abstract}
This is a cross-sectional study carried out with 258 teachers in nine public schools located in the cities of Campinas and São J osé do Rio Pardo, in the State of São Paulo, in order to describe their socio-demographic profiles, lifestyles and health and working conditions. The sample was comprised mostly by females (81.8\%), married $(60.8 \%)$, averaging 41.4 years of age (SD 9.2), working out $(56.6 \%)$, with leisure time $(93.4 \%)$ and performing home duties (88.4\%). In terms of health, $20.9 \%$ did not sleep well at night and $82.1 \%$ had one of following diseases diagnosed by a physician: musculoskeletal and respiratory diseases (27.1\%); injuries due to accidents and digestive diseases (22.1\%), and mental disorders (20.9\%). These diseases were related to the professional risks that were described: repetitive movements, chalk dust, stressing work, long working hours, work in more of one school and low wage. It was concluded that teachers are exposed to risks at schools and that prevention and health care policies should be taken by the authorities.
\end{abstract}

\begin{abstract}
RESUMEN
Se trata de un estudio transversal realizado en nueve escuelas estatales de Campinas y Sao José do Rio Pardo, con 258 profesores con el objetivo de caracterizar el perfil sociodemográfico, estilos de vida, condiciones de salud y de trabajo. La muestra estuvo constituida por mujeres $(81,8 \%)$ y hombres $(18,2 \%)$, siendo casados $(60,8 \%)$, con un promedio de edad de 41,4 años (DP $9,2)$, que realizaban actividad física $(56,6 \%)$, descanso $(93,4 \%)$ y tareas domésticas $(88,4 \%)$. En cuanto a la salud, $20,9 \%$ no dormían bien por la noche; $82,1 \%$ tenían enfermedad con diagnóstico médico: músculo-esquelético y respiratoria $(27,1 \%)$; accidentes y enfermedades digestivas $(22,1 \%)$ y trastornos mentales $(20,9 \%)$. Las referidas enfermedades estaban relacionadas a los riesgos relatados: movimientos repetitivos, presencia de polvo de tiza, trabajo estresante, jornadas largas, actividad en más de una escuela y baja remuneración. Se concluye que los profesores estaban expuestos a riesgos en las escuelas y que las medidas de promoción a la salud y prevención deberían ser tomadas por los gobernantes.
\end{abstract}

\author{
DESCRIPTORES \\ Salud laboral. \\ Condiciones de trabajo. \\ Estado de salud. \\ Estilo de vida. \\ Condiciones sociales.
}

\footnotetext{
* Extraído da dissertação "Fatores associados à capacidade para o trabalho dos professores de escolas estaduais de dois municípios do estado de São Paulo", Departamento de Enfermagem, Faculdade de Ciências Médicas, Universidade Estadual de Campinas, $2007 .{ }^{1}$ Enfermeira mestre pelo Departamento de Enfermagem da FCM - Universidade de Campinas; Ex-Bolsista da CAPES. Campinas, SP, Brasil. tatigio@fcm.unicamp.br ${ }^{2}$ Professora Associada do Departamento de Enfermagem da FCM - Universidade Estadual de Campinas. Departamento de Enfermagem da FCM - UNICAMP. Campinas, SP, Brasil. inesmon@fcm.unicamp.br
} 


\section{INTRODUÇÃO}

O exercício do magistério é uma função antiga e os problemas decorrentes dela, a acompanham desde os primórdios. Alguns estudos brasileiros demonstram uma relação importante entre a saúde dos professores e suas condições de vida e de trabalho.

Em pesquisa com professores da rede particular de ensino na Bahia foram relatados como principais queixas a presença de poeira (pó de giz), ritmo acelerado de trabalho, esforço físico e ambiente de trabalho estressante. As referidas condições acarretam danos à saúde dos professores levando-os a sentirem estresse, faringite, lombalgia, doenças do aparelho locomotor e circulatório e neuroses ${ }^{(1)}$.

Outro estudo semelhante realizado também na Bahia ${ }^{(2)}$ relatou que as queixas mais comuns dos professores estavam relacionadas com o uso da voz, a postura corporal e problemas psicossomáticos e de saúde mental.

Os problemas relativos ao uso constante da voz também foram freqüentes e em um estudo realizado com 451 educadores do ensino municipal de Mogi das Cruzes, interior de São Paulo, 80,7\% deles relataram algum problema com a voz, como uma eventual disfonia, em algum momento da vida profissional(3).

Sobre a saúde mental, o estresse pode levar a uma síndrome especial de esgotamento do trabalho também conhecida como burnout ${ }^{(4)}$. A indisciplina de alguns alunos, assim como o mau comportamento e o desrespeito com os educadores durante a aula podem gerar um mal estar diário levando-o à síndrome de burnout que seria um estado físico e mental de total esgotamento(4).

Os fatores psíquicos que mais afetavam os professores da rede municipal da Bahia eram

...as tarefas extra-classe, reuniões e atividades adicionais, problemas com alunos que chegam até ameaças verbais e físicas, pressão do tempo etc ${ }^{(5)}$.

Aliada ao desgaste mental da carreira do professor, ainda persiste a falta de reconhecimento da sociedade e a não valorização deste profissional, pois

infelizmente, ocorreu uma deterioração das condições da formação e da prática profissional do professorado no Brasil, hoje tão desvalorizado no próprio universo acadêmico, na mídia e na sociedade em geral(6).

A investigação do trabalho do professor, em qualquer lugar do mundo, pode ser a chave para a transformação das desigualdades no país, assim como para seu crescimento. Destaque para o Instituto de Estatística da Organização das Nações Unidas para a Educação, Ciência e Cultura (UIS-UNESCO) ${ }^{(7)}$ que realizou um estudo e avaliou um declínio de professores/ educadores e, caso não se invista em educação, principalmente na figura do profissional, dentro de pouco tempo, não haverá número suficiente para garantir a universalização da educação básica. Existe uma estimativa de que, até 0 ano 2015, o Brasil terá que contratar 396 mil novos professores para garantir uma educação para todos ${ }^{(7)}$.

0 objetivo dessa pesquisa foi a caracterização do perfil sociodemográfico, estilo de vida, condições de trabatho e o desgaste da saúde dos professores de escolas estaduais de ensino fundamental e médio.

Este é um subprojeto de pesquisa do Projeto Capacidade para 0 trabalho entre trabalhadores de diferentes ramos produtivos, coordenado pela Profá. Drạ. M aria Inês Monteiro, no Grupo de Estudos e Pesquisas em Saúde e Trabalho, do Departamento de Enfermagem da Faculdade de Ciências M édicas - UNICAM P.

\section{MÉTODO}

Estudo epidemiológico transversal( ${ }^{(8)}$ descritivo, realizado em duas cidades do interior do estado de São Paulo, Campinas e São José do Rio Pardo, englobando nove escolas estaduais de ensino fundamental e/ou médio; sendo quatro em região mais central com infra-estrutura de saneamento básico, rede de esgoto, asfalto e energia elétrica e cinco escolas de regiões periféricas, com menor grau de infra-estrutura.

Foram escolhidas duas cidades, uma de grande e outra de médio porte ${ }^{(a)}$, pois os dados sociodemográficos, de estilo de vida e os relativos ao trabalho dos professores de ambos municípios poderiam ser diferentes, além disso, existe uma carência de estudos comparativos de populações de procedências distintas.

0 critério de escolha das escolas foi intencional com cota mínima de pelo menos 100 entrevistas por cidade de diferentes tamanhos. Equilibrou-se uma quantidade de professores por escolas em cada cidade levando em consideração a divisão por regiões central e periférica. EscoIheu-se quatro escolas em Campinas ao se observar que existia mais professores por escola nesta cidade do que em São José do Rio Pardo.

Foram efetuadas visitas prévias nas escolas escolhidas para solicitar a autorização para a aplicação dos questionários. Optou-se por distribuir os questionários durante as reuniões semanais de HTPC (hora de trabalho pedagógico coletivo) devido a dificuldade em encontrar os professores nos intervalos de aulas. Todos os participantes assinaram um termo de consentimento que foi destacado a fim de manter 0 anonimato.

(a)Segundo dados do IBGE, em 2005, a estimativa populacional para a cidade de Campinas foi 1.045.706 de habitantes e em São José do Rio Pardo a estimativa ficou em 53.522 de habitantes. 
A população de educadores das cinco escolas escolhidas em São José do Rio Pardo era de 221 professores e, nas quatro escolas escolhidas em Campinas foi de 247, totalizando 468 professores nas duas cidades.

Foram incluídos na pesquisa todos os professores das nove escolas estaduais, de ambos os sexos, de todas as idades, que ministravam qualquer disciplina tanto para o ensino fundamental e médio e que aceitaram espontaneamente participar da mesma, após assinarem um termo de consentimento livre e esclarecido.

A coleta de dados foi realizada pela primeira autora no período de agosto a dezembro de 2005.

Quanto aos aspectos éticos dessa pesquisa, foram respeitadas as determinações do Conselho Nacional de Saúde (Resoluções 196/97 e 251/97), a pesquisa foi aprovada pelo Comitê de Ética em Pesquisa (CEP - Parecer Projeto 286/2004) da Faculdade de Ciências M édicas da Universidade Estadual de Campinas - FCM / UNICAMP.

Elaborou-se um banco de dados através do aplicativo Microsoft Excel ${ }^{\circledR}$ e o programa computacional utilizado para a análise estatística dos resultados foi o SAS ${ }^{\circledR}$ - System for W indows (Statistical Analysis System, versão 8.02).

Os instrumentos utilizados para a coleta de dados foram os seguintes:

- QSETES- Questionário com dados sociodemográficos, estilo de vida, trabalho e aspectos de saúde e riscos ocupacionais desenvolvido por Monteiro ${ }^{(b)}$.

- OSQ - Occupational Stress Questionnaire(9).

- Análise ergonômica do trabalho (AET) ${ }^{(10)}$.

Foram realizados os seguintes testes estatísticos: Quiquadrado, Mann-Whitney e Kruskal-Wallis, além do coeficiente de correlação de Spearman, a análise de regressão linear e a análise de regressão logística univariada.
0 nível de significância para os testes estatísticos foi de $5 \%$, ou seja, $p \varangle 0,05$.

\section{RESULTADOS}

Participaram da pesquisa respondendo ao questionário 258 (55,1\%) professores. Em relação aos $210(44,9 \%)$ sujeitos que não participaram da pesquisa, $11,1 \%$ recusaram-se verbalmente, $14,1 \%$ estavam de licença médica no período da coleta de dados, 5,1\% não foram encontrados nas escolas em nenhum momento pela pesquisadora, $12,2 \%$ não devolveram os questionários e $2,4 \%$ devolveram sem preenchê-los. Não houve diferenças entre sexo e idade entre os professores participantes e os não participantes.

A média de idade foi de 41,4 anos (DP 9,4), a maioria era do sexo feminino (81,8\%), eram casados $(60,9 \%)$ e com filhos $(66,3 \%)$.

A modalidade de ensino mais freqüente foi dos professores que atuavam tanto no fundamental II (da quinta a oitava série) como no ensino médio e envolveu $27,1 \%$ dos entrevistados, seguidos daqueles que atuavam somente no fundamental I (ensino da primeira a quarta série) que eram $25,6 \%$.

Dos que responderam ao questionário, 7,3\% exerciam outra função na escola como direção, vice-direção, coordenação pedagógica e trabalho na biblioteca (professor readaptado) e por isso não responderam o item de atuação de modalidade de ensino. E dos professores eventuais, $64,7 \%$ também não especificaram a atuação do ensino por se tratar de um professor que é convocado para ministrar aula em caráter emergencial, para substituir os professores efetivos ou de contratação provisória.

A Tabela 1 apresenta os dados sociodemográficos dos professores e a tabela 2 destaca as características do trabalho na escola em Campinas e São José do Rio Pardo.

Tabela 1 - Distribuição dos professores segundo variáveis sociodemográficas - Campinas e São José do Rio Pardo 2005

\begin{tabular}{llcc}
\hline Variáveis & Categorias & $\boldsymbol{n}$ & $\boldsymbol{\%}$ \\
\hline Sexo & Feminino & 211 & 81,8 \\
& Masculino & 47 & 18,2 \\
Faixa etária & & & 12 \\
(anos) & $<30$ & 31 & 30,6 \\
& $30+40$ & 79 & 36,1 \\
& $40+50$ & 93 & 21,3 \\
Estado conjugal & $\geq 50$ & 55 & 60,9 \\
& & & 26,0 \\
& Casado/Vive com o companheiro & 157 & 11,0 \\
& Solteiro & 67 & 2,1 \\
Filhos & Divorciado & 28 & 66,3 \\
& Viúvo & 6 & 33,7 \\
\hline Total & Sim & 171 & 100,00 \\
\hline
\end{tabular}

(b) Monteiro MI. Instrumento para coleta de dados sociodemográficos, aspectos de saúde, trabalho e estilo de vida - QSETS. Campinas; 1996, atualizado em 2005 
Tabela 2 - Características relativas à vida laboral dos professores - Campinas e São José do Rio Pardo - 2005

\begin{tabular}{lccc}
\hline Características do trabalho & $\boldsymbol{n} *$ & Média & Desvio-padrão \\
\hline Idade que começou a trabalhar & 258 & 18,6 & 4,1 \\
Tempo na função de professor & 258 & 14,2 & 8,2 \\
Tempo do professor na escola pela qual participou da pesquisa & 258 & 4,6 & 5,2 \\
Carga horária semanal na escola & $251 *$ & 26,2 & 10,1 \\
Carga horária semanal total (mais de uma escola) & $252 *$ & 35,1 & 12,2 \\
\hline
\end{tabular}

$\boldsymbol{n}^{\star}=251$ e 252 devido a resposta deixada em branco em alguns questionários de professores eventuais que não possuíam uma carga fixa de trabalho na escola que atuava, justamente por trabalhar como substituto de outros educadores concursados que possuem carga de trabalho fixa e que por algum motivo se ausentam no trabalho da escola.

Em média, os professores atuavam nessa função há 14,2 anos (DP 8,2) e, na escola atual, lecionavam em média há 4,6 anos (DP 5,2). Aqueles cujo vínculo de trabalho estável como efetivos eram $47,7 \%$; no regime de contratação provisória $45,7 \%$ e, apenas $6,6 \%$ pertenciam a categoria de professor eventual.

A faixa salarial predominante referida pela maioria dos entrevistados (54,7\%) foi de $R \$ 800,00$ a $R \$ 1499,00$ e $20,9 \%$ recebiam até $R \$ 799,00$. Na época da pesquisa 0 salário mínimo vigente no Brasil em dólares era de US\$131,55(c) e em reais, $R \$ 300,00$.

A carga horária média semanal dos professores em apenas uma escola era de 26,2 horas (DP 10,1), e a jornada média de trabalho semanal em mais de uma escola era de 35,1 horas (DP 12,2).

Concluíram a educação superior $95,7 \%$ dos professores e, desses, 15,1\% cursaram pós-graduação (especialização, mestrado e/ou doutorado).

Quanto ao estilo de vida referido, a maioria dos professores realizava tarefas domésticas em casa $(88,4 \%)$, possuíam atividades de lazer $(93,4 \%)$ e $56,6 \%$ praticavam atividade física regularmente pelo menos três vezes por semana.

Em relação aos hábitos de sono relatados, em torno de $20,9 \%$, não conseguiam dormir bem após o trabalho, durante a noite, e a média de sono por noite durante a semana era de 6,8 horas (DP 1,2). Quanto ao tabagismo e ingestão de bebidas alcoólicas, constatou-se que $27,5 \%$ ingeriam bebidas alcoólicas e 9,3\% fumavam em média 13,3 cigarros/ dia (DP 8,4).

A falta de recursos materiais para ministrar aulas foi relatada por $41,3 \%$ desses professores e 0 ambiente físico da escola inadequado por $44,6 \%$.

As condições inadequadas agregadas a outros fatores como a presença de ruído, uso constante da voz no trabaIho, movimentos repetitivos, lidar com os alunos em sala

(c)Fonte: Indicadores - Cotação Dólar. Banco Central. Média dos valores do dólar nos últimos cinco anos. http:www.acinh.com.br/cotacao.html [citado em abril de 2007]. de aula, principalmente com a indisciplina deles, podem se tornar fatores estressantes no trabalho do professor. $\mathrm{Na}$ amostra estudada $95,4 \%$ dos professores consideravam cansativo e desgastante o seu trabalho podendo gerar conseqüências relativas à saúde dos mesmos sendo que, $82,3 \%$ tinham pelo menos uma doença diagnosticada pelo médico; $62,1 \%$ relataram a presença de dor em algum local do corpo nos últimos seis meses e $51,6 \%$ na última semana, além do uso de medicamentos $(50,8 \%)$.

As doenças com diagnóstico médico mais citadas foram: músculos-esqueléticos e respiratórias $(27,1 \%)$; acidentes e doenças digestivas $(22,1 \%)$, transtornos mentais $(20,9 \%)$, cardiovasculares $(19,4 \%)$, neurológicas $(18,6 \%)$, endócrinas $(17,4 \%)$, de pele $(16,3 \%)$ e genitourinárias $(11,2 \%)$.

Em relação aos dados sobre o questionário $\mathrm{OSQ}^{(9)}$, $58,1 \%$ dos professores referiram uma pressão do tempo interna constante para terminar o trabalho rapidamente. Consideraram o trabalho mentalmente extenuante $46,1 \%$ e, fisicamente extenuante, 30,6\%. Quanto aos sintomas de estresse como tensão, inquietação, nervosismo, ansiedade, insônia e preocupações sentidos na última semana, $33,3 \%$ relataram ter sentido esses sintomas até certo ponto, enquanto $32,1 \%$ manifestaram muito ou bastante e $34,5 \%$ referiram não ter nenhum ou somente um pouco dos sintomas estressantes. Os professores satisfeitos com a vida atual eram $54,7 \%$ enquanto que os satisfeitos com o trabalho atual na escola eram $45,7 \%$.

Tabela 3 - Distribuição dos professores em relação aos riscos no trabalho - Campinas e São José do Rio Pardo 2005

\begin{tabular}{lcrr}
\hline Riscos no Trabalho & Sim/Não & $\boldsymbol{n}$ & \multicolumn{1}{c}{ \% } \\
\hline Ruído & Sim & 254 & 98,45 \\
& Não & 4 & 1,45 \\
Uso da voz & Sim & 258 & 100,00 \\
Movimentos repetitivos & Sim & 255 & 98,84 \\
& Não & 3 & 1,16 \\
Uso do computador & Sim & 178 & 69,99 \\
& Não & 80 & 31,01 \\
Tarefas monótonas & Sim & 234 & 90,70 \\
Trabalho estressante & Não & 24 & 9,30 \\
& Sim & 249 & 96,51 \\
Total & Não & 9 & 3,49 \\
\hline
\end{tabular}


Em junho de 2006, foram observados cinco professores, pelo menos um de cada categoria do ensino fundamental I, II e médio, em duas escolas de São José do Rio
Pardo. Através dessas observações realizou-se a análise ergonômica do trabalho (AET) ${ }^{(10)}$ do professor, como descrita na Figura 1.

Análise Ergonômica do Trabalho (AET) do professor

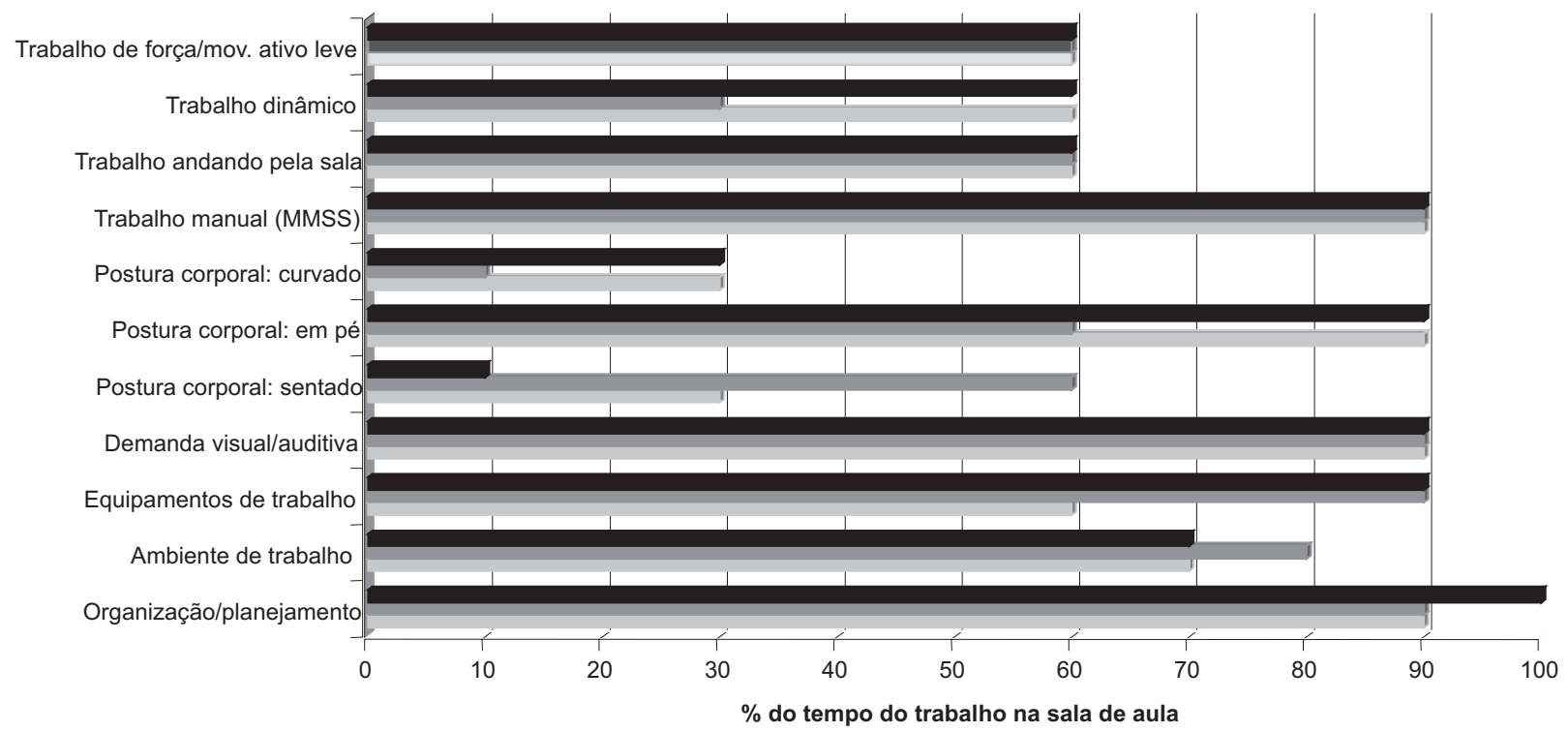

E.MÉDIO E.FUND II E.FUND I

Figura 1 - Análise ergonômica do trabalho dos professores - São José do Rio Pardo - 2006

\section{DISCUSSÃO}

Todos os participantes da pesquisa atuavam em escolas estaduais de Campinas e São José do Rio Pardo e os dados gerais relativos às duas amostras foram semelhantes.

A maioria dos sujeitos eram mulheres, casadas e com elevada escolaridade. A predominância do sexo feminino é semelhante ao relatado por outros autores em pesquisas realizadas com professores ${ }^{(1-2,5)}$ que destacam a grande presença das mulheres nessa profissão, fato que está relacionado ao papel cultural da mulher na sociedade de educar e cuidar dos filhos, sendo então, essa profissão considerada como uma extensão do trabalho doméstico.

A elevada escolaridade entre os professores, provavelmente está relacionada com a aprovação em dezembro de 1996, da Lei de Diretrizes e Bases da Educação ${ }^{(11)}$ que passou a exigir nas escolas particulares e públicas o nível superior para todos os professores que atuavam no ensino básico, que inclui o fundamental I e o II.

A participação feminina no mercado de trabalho continua tendo um importante papel social na complementação do orçamento familiar, devido ao fato que mais da metade $(57,3 \%)$ das professoras eram casadas ou viviam com companheiros e $85,9 \%$ delas possuíam filhos.
Tanto em Campinas como em São José do Rio Pardo, mais da metade dos professores $(53,9 \%)$ trabalhavam simultaneamente em outra escola e, desses, $60,4 \%$ atuavam em outra escola estadual e, 36,6\%, na rede particular ou municipal de ensino. Além disso, 15,9\% desenvolviam outras atividades remuneradas, além da docência. Essa alta porcentagem de educadores que trabalhavam em duas ou mais escolas ou tinham outra atividade remunerada pode ser um indicativo de uma necessidade de complementação de renda familiar, através de outros trabalhos, inclusive fora da área de ensino. Esse dado também foi evidenciado no estudo com professores da rede particular da Bahia (2), demonstrando que tanto na rede estadual como na particular de ensino ocorre uma baixa remuneração desses profissionais.

O tempo médio de atuação dos professores foi de 14,6 anos (DP 8,2) e na escola atual onde lecionavam foi de 4,6 anos (DP 5,2 ), os quais foram semelhantes às médias encontradas em um outro estudo realizado na Bahia ${ }^{(1)}$ com educadores da rede particular de ensino.Também nas escolas estaduais existe uma grande rotatividade dos professores não efetivos, levando-os a mudarem sempre de ambiente de labor, submetidos assim, a uma maior diversidade de riscos, inclusive 0 de trabalho estressante ${ }^{(12)}$.

Abordar 0 estresse no dia-a-dia do trabalho torna-se um fenômeno complexo porque engloba aspectos biológi- 
cos, psíquicos e sociais em qualquer ser humano e pode estar presente na maioria das profissiões que lidam com pessoas como os enfermeiros ${ }^{(13)}$ e também nos professores.

A carga de trabalho semanal média de 35,1 horas (DP $12,2)$ encontrada em mais da metade do professores $(53,9 \%)$ foi semelhante a outro estudo com professores da rede particular da Bahia no qual os autores ${ }^{(2)}$ afirmam que a essa carga horária ainda devem ser somadas as horas para a preparação de aulas, os deslocamentos de uma escola para outra e as atividades domésticas. As atividades domésticas ocupam de duas a três horas por dia do tempo dos professores ${ }^{(14)}$. De maneira geral, os professores parecem possuir uma sobrecarga de trabalho advinda das atividades extra-escolares somadas com as horas de trabalho na escola.

Encontrou-se uma média 3,2 horas (DP 2) diárias de dedicação dos educadores com os afazeres domésticos, sendo mais evidente nas mulheres, pois, $93 \%$ delas declararam que realizavam tarefas domésticas, enquanto que somente $68,1 \%$ dos homens relatavam realizar atividade em casa, confirmando que, em geral, a dupla jornada de trabalho afeta o sexo feminino. Foi realizado o teste Qui-quadrado com $p$-valor de 0,0001 para tarefas domésticas e sexo, sendo significante para as professoras que realizavam mais tarefas domésticas. A responsabilidade pelo trabalho doméstico também se mostrou relevante para as mulheres que eram professoras na rede municipal do ensino de Vitória da Conquista, Bahia ${ }^{(15)}$.

Quanto ao estilo de vida, foi observada a similaridade entre homens e mulheres quanto ao hábito de fumar $(9,3 \%)$ e atividades de lazer (93,5\%). 0 hábito prejudicial de fumar era inferior à média brasileira que vária de 12,9 a 25,2\%(16).

No entanto, em relação as atividades físicas, a proporção de homens que a praticavam eram $61,7 \%$, e enquanto que somente $55,5 \%$ das mulheres desenvolviam alguma atividade física. A porcentagem de mulheres que não conseguiam dormir bem após o trabalho $(22,3 \%)$ foi maior que a relatada pelos homens (14,9\%). Esses dois fatores de estilo de vida: atividade física e dificuldade de dormir, demonstram que a mulher quando inserida no mercado de trabalho muitas vezes, possui dificuldades de encontrar um período do dia ou da semana para cuidar de si mesma e para a prática de atividades físicas, ao contrário da maioria dos homens, que realizavam em menor porcentagem os afazeres da casa, tendo provavelmente maior tempo livre e menor desgaste pela realização das tarefas domésticas.

Segundo, dados da Organização Mundial da Saúde a prática regular de atividade física beneficia a preservação da saúde, porque reduzem os riscos de adoecimento por diabetes, hipertensão e problemas cardiovasculares, além de prevenir as dores músculos-esqueléticas promo- vendo o bem estar psicológico, reduzindo o estresse, a ansiedade e a depressão(17). Notou-se uma porcentagem de $43,4 \%$ de professores sedentários e uma grande quantidade de doenças com diagnóstico médico $(82,3 \%)$ relatadas pelos professores das escolas estaduais de dois municípios paulistas.

No ambiente da escola, os possíveis riscos de trabaIho a que estavam sujeitos os professores foram a presença de ruído na escola, o uso constante da voz, os movimentos repetitivos, o uso do computador, as tarefas monótonas e o trabalho estressante. Além disso, ao se conceituar o risco, entende-se que seja a probabilidade de um dano (lesão) à saúde que ocorra ao trabalhador em qualquer local de trabalho(18).

0 uso da voz constante foi relatado por todos os professores, o que era esperado pelas características da atividade profissional e $10,1 \%$ dos educadores mencionavam algum problema como fendas e calos nas cordas vocais ou alteração da voz como rouquidão constante e até afonia, ausência da voz, em algum momento de sua vida profissional, mesmo não existindo no questionário uma questão específica sobre esse problema de saúde. Para um estudo ${ }^{(3)}$, os problemas de voz com os profes-sores de Mogi das Cruzes, São Paulo, confirmou que a disfonia era elevada.

Os movimentos repetitivos de escrever e apagar a lousa e o contato direto com a poeira do giz, andar pela sala de aula, ficar muito tempo em pé, curvar-se nas carteiras dos alunos foram relatados por quase todos os professores $(98,8 \%)$. Acrescido de algumas tarefas repetitivas como corrigir cadernos, provas, exercícios dos alunos e escrever em cadernetas foram mencionadas por $90,7 \%$, além do uso diário do computador (69,9\%). Em relação aos educadores que sentiram dor nos últimos seis meses e na última semana, mais da metade deles $(57,7 \%)$ referiu dor justamente no local do corpo relacionado com a musculatura esquelética da coluna cervical, coluna lombar, membros superiores e inferiores, seguida de cefaléia $(34,4 \%)$.

O ruído na escola foi relatado por $98,5 \%$ dos sujeitos e apesar de ser um problema majoritariamente encontrado nas indústrias em geral e na construção civil, ele pode ser encontrado em qualquer local de trabalho como orquestras, bares, restaurantes e escolas ${ }^{(19)}$ onde foi o local de trabalho dessa pesquisa.

0 barulho, segundo a Agência Européia para Saúde e Segurança no Trabalho ${ }^{(19)}$, não precisa ser alto para causar problemas no local de trabalho porque pode interagir com outros riscos na escola e intensificar os danos aos trabalhadores, podendo se tornar um fator agravante do estresse relacionado ao trabalho. 0 ruído como causador de danos foi reconhecido não somente na agricultura, transporte, indústria e construção, mas também nas escolas, hospitais, bares e restaurantes ${ }^{(19)}$. 
0 fato da maioria dos professores $(96,5 \%)$ considerar o trabalho na escola estressante pode ter uma relação com 0 aparecimento de transtornos mentais com diagnóstico médico, referidos por $20,9 \%$ dos entrevistados. Uma porcentagem relativamente alta de problemas mentais como depressão leve, tensão, insônia e depressão severa foram citados pelos professores participantes da pesquisa como sendo diagnosticadas pelos médicos e desses 74,1\% usavam medicamento antidepressivo.

Deve ser destacada como limitação do estudo o fato de ser um estudo transversal, que permite avaliar os dados existentes no momento da coleta.

Em relação à adesão dos professores a pesquisa incidência de $55,1 \%$ - pode ser devido ao período, pois normalmente, com a proximidade do final do ano existe uma quantidade maior de faltas devido ao cansaço dos professores, e os meses mais críticos seriam os do último trimestre correspondente ao meses de outubro, novembro e dezembro, devido ao possível incremento das atividades extra-classe, como a correção de provas e/ ou trabaIhos dos alunos ${ }^{(20)}$.

A análise dos dados da AET ${ }^{(10)}$ destacou no item organização/planejamento referente a observação do trabaIho do professor na sala aula, o professor do ensino fundamental I foi o que apresentou maior porcentagem de tempo (100\%) na organização da sala de aula, justamente por se tratar dos primeiros anos da alfabetização das crianças e o desgaste físico e mental para o preparo das aulas, o lidar com crianças pequenas (sete a dez anos de idade) e o tempo para ministrar o conteúdo das aulas dos mesmos foi ligeiramente maior em relação aos professores do ensino fundamental Il e do médio.

No entanto, houve equivalência no tempo (90\%) do desempenho do trabalho manual e na demanda visual/ auditiva para os professores do ensino fundamental I, II e médio. Para o trabalho manual, considerou-se o tempo dos professores usando os membros superiores para escrever e apagar a lousa e para a demanda visual/auditiva foi considerada a porcentagem de tempo da aula que os professores usaram a voz.

Quanto a porcentagem do tempo durante o período de aula ${ }^{(c)}$ que foram observadas as posturas corporais curvadas e em pé dos professores, encontrou equivalência de $30 \%$ na posição curvada dos professores do fundamental I e do médio e também em quase todo o tempo (90\%) que permaneceram na posição em pé.

De maneira geral, a análise ergonômica demonstrou que tanto os professores do ensino fundamental I e II como do médio, desempenhavam atividades com posturas relativamente desconfortáveis, pois não se observou entre uma aula e outra com os professores do fundamental I, II e médio, qualquer forma de relaxamento do esforço físico desenvolvido durante as aulas ministradas e observadas pela primeira autora.

\section{CONCLUSÃO}

Encontrou-se como perfil sociodemográfico dos professores a sua maioria eram mulheres sendo que mais da metade delas eram casadas, possuíam elevada porcentagem de nível superior completo e com mais de dez anos na área de docência, além de receberem baixa remuneração, possuíam longas jornadas de trabalho semanal.

$\mathrm{Na}$ sua maioria os professores possuíam estilos de vida precários com relativa presença de atividade física, poucas horas de sono durante a noite e muitos problemas de saúde, destacando os transtornos músculosesqueléticos, respiratórios e mentais.

Além disso, os fatores de riscos mais apontados foram: ruído, uso constante da voz, movimentos repetitivos, trabalho estressante, cansativo e desgastante tanto mental como fisicamente.

Diante dessas características pode-se concluir que o que ocorre especificamente com esses professores dessas nove escolas estaduais, pertencentes aos dois municípios paulistas, podem se tornar um evento presente na vida de todos os professores que atuam nas escolas públicas do Brasil, e consequentemente, tornar-se um problema de saúde coletiva desse trabalhador da educação e que merece ser destacado e levado ao conhecimento das autoridades nacionais para impulsionar programas com grupos de trabalho e estudos, que permitam a continuidade de pesquisas como essa que possam futuramente intervir com estratégias de promoção à saúde e mudanças nas condições de trabalho dos professores das escolas públicas brasileiras. 


\section{REFERÊNCIAS}

1. Silvany Neto AM, Araújo TM, Dutra F, Azi G, Alves R, Kavalkievicz $C$, et al. Condições de trabalho em professores da rede particular de ensino na Bahia: estudo piloto. Rev Bras Saúde Ocupac.1998;24(91/92):115-24.

2. Delcor NS, Araújo TM, Reis EJFB, Porto LA, Carvalho FM, Silva MO, et al. Condições de trabalho e saúde dos professores da rede particular de ensino de Vitória da Conquista, Bahia, Brasil. Cad Saúde Pública. 2004;20(1): 187-96.

3. Fuess VLR, Lorenz MC. Disfonia em professores do ensino municipal: prevalência e fatores de risco. Rev Bras Otorrinolaringol. 2003;69(6):807-12.

4. Seligmann-Silva E. Desgaste mental no trabalho dominado. Rio de Janeiro: Ed. UFRJ;1994.

5. Reis EJFB, Carvalho FM, Araújo TM, Porto LA, Silvany Neto AM. Trabalho e distúrbios psíquicos em professores da rede municipal de Vitória da Conquista, Bahia, Brasil. Cad Saúde Pública. 2005;21(5):1480-90.

6. Meleiro AMAS. 0 stress do professor. In: Lipp M, organizador. 0 stress do professor. 2 $\underline{a}$ ed. Campinas: Papirus; 2003. p. 11-27.

7. UNESCO. Institute for Statistics. UIS-UNESCO. Teachers and educational quality: monitoring global needs for 2015 [text on the Internet]. Montreal; 2006. [cited 2006 Oct 31]. Available from: http://www.uis.unesco.org/ publications/teachers2006

8. Checkoway H, Pearce N, Crawford-Brown DJ. Research methods in occupational epidemiology. New York: Oxford University Press; 1989.

9. Elo A-E, Leppänen A, Lindström K, Ropponen T. Occupational Stress Questionnaire - OSQ. Helsink: Finnish Institute of Occupational Health; 1992.

10. Rohmert W, Landau K. A new technique for job analysis. London: Taylor \& Francis; 1983.

11. Brasil. Lei n. 9.394, de 1996. Lei de Diretrizes e Bases da Educação - LDB. Estabelece as diretrizes e bases da educação nacional, e legislação correlata. 2a ed. Brasília: Câmara dos Deputados, Coordenação de Publicações; 2001.
12. Machado CM. O estresse extra-classe. Belo Horizonte: Sindicato dos Professores de Minas Gerais; 1993.

13. Costa JRA, Lima JV, Almeida PC. Stress no trabalho do enfermeiro. Rev Esc Enferm USP. 2003;37(3):63-71.

14. Gomes L. Trabalho multifacetado de professores/as: a saúde entre limites [dissertação]. Rio de Janeiro: Escola Nacional de Saúde Pública, Fundação Oswaldo Cruz; 2002.

15. Araújo TM, Godinho TM, Reis EJFB, Almeida MMG. Diferenciais do gênero no trabalho docente e repercussões sobre a saúde. Ciênc Saúde Coletiva. 2006; 11 (4):1117-29.

16. Brasil. Ministério da Saúde. Instituto Nacional do Câncer (INCA). Inquérito domiciliar de risco e morbidade referida de doenças e agravos não transmissíveis em 15 capitais e Distrito Federal. 2002-2003 [texto na Internet]. Brasília; 2003. [citado 2006 set. 28]. Disponível em: http://www.inca.gov.br/tabagismo frameset. asp? item $=$ dados\&link $=$ brasil.. htm

17. World Health Organization (WHO). Move for health: benefits of physical activity [text on the Internet]. Geneva; 2006. [cited 2006 Feb 11]. Available from: http://ww w.who.int/moveforhealth/advogacy/ information_sheets/benefits/en/index.html

18.European Agency for Safety and Health at Work. Management of occupational safety and health in the education sector. Facts [serial on the Internet]. 2003 [cited 2005 Oct 15];(45):[about 2 p.]. Available from: http://osha. europa.eu/publications/factsheets/45/ index.htm?set_ language $=$ en

19. European Agency for Safety and Health at Work. An introduction to noise at work. Facts [serial on the Internet]. 2003 [cited 2005 Oct 15];(56):[about 4 p.]. Available from: http://osha.europa.eu/publications/factsheets/56 index.htm?set_language =en

20. Esteve JM. O mal-estar docente: a sala de aula e a saúde dos professores. Bauru: EDUSP; 1999. 